\title{
Special issue of OQEL on silicon photonics and nanophotonics
}

\author{
Pavel Cheben • Jens H. Schmid • \\ Trevor M. Benson - Richard A. Soref
}

Published online: 19 September 2012

(C) Her Majesty the Queen in Right of Canada 2012

For more than 40 years silicon has been the mainstream material in the electronic industry, revolutionizing the way we live. The pioneering work by Soref and his colleagues in mid 1980s opened exciting prospects for silicon to expand its dominance into the field of photonics. Silicon photonics has been the subject of intense research activity in both industry and academia, covering diverse areas such as optical waveguides, light sources, modulators, switches, detectors, couplers, photonic crystals, diffraction gratings, subwavelength structures, spectral filters, wavelength multiplexers, polarization circuits, sensors, transceivers, and various sub-systems. Today, silicon photonics is an extremely active and firmly established research field and silicon photonics circuits are emerging as a compelling technology for energy-efficient high-speed computing, signal processing and communications. Integration and scaling advantages together with the added benefit of leveraging the enormous existing CMOS manufacturing infrastructure are obvious industrial benefits of silicon that no other photonic material presently can match.

The aim of this Special Issue is to record some of the remarkable recent progress in silicon photonics and nanophotonics and point to future trends in this rapidly evolving field. All the articles in this issue are invited review papers by leading authorities and research groups in this field from universities, industry and government laboratories.

P. Cheben $(\bowtie) \cdot$ J. H. Schmid

National Research Council Canada, 1200 Montreal Rd., M-50, Ottawa, ON K1A 0R6, Canada e-mail: Pavel.Cheben@nrc-cnrc.gc.ca

J. H. Schmid

e-mail: jens.schmid@nrc.ca

T. M. Benson

Department of Electrical and Electronic Engineering, Faculty of Engineering, University of Nottingham, University Park, Nottingham, NG7 2RD, UK

e-mail: Trevor.Benson@nottingham.ac.uk

R. A. Soref

The University of Massachusetts at Boston, 100 Morrissey Boulevard, Boston, MA 02125, USA

e-mail: soref@rcn.com 
The Invited Papers of this Special Issue are:

Fast light-emitting silicon-germanium nanostructures for optical interconnects, by D.J. Lockwood and L. Tsybeskov

An optically pumped nanophotonic InP/InGaAlAs optical amplifier integrated on a SOI waveguide circuit, by M. Tassaert, S. Keyvaninia, D. VanThourhout, W.M.J. Green, Y. Vlasov and G. Roelkens

Single etch grating couplers for mass fabrication with DUV lithography, by $R$. Halir, L. Zavargo-Peche, D.-X. Xu, P. Cheben, R. Ma, J.H. Schmid, S. Janz, A. Densmore, A. Ortega-Moñux, Í. Molina-Fernández, M. Fournier and J.-M. Fédeli

Hybrid integration for silicon photonics applications, by L. Grenouillet, T. Dupont, P. Philippe, J. Harduin, N. Olivier, D. Bordel, E. Augendre, K. Gilbert, P. Grosse, A. Chelnokov and J.M. Fedeli

Grating couplers for thick SOI rib waveguides, by C. Alonso-Ramos, A. Ortega-Moñux, Í. Molina-Fernández, P. Cheben, L. Zavargo-Peche, R. Halir, N. Kim, S. Janz, D.-X. Xu and B. Lamontagne

Validation of an analytical model of Si-ring resonators for designing a $1 \times 8$ multiplexer in SCISSOR configuration, by C. Chauveau, P. Labeye, J.-M. Fedeli, J. Hazart, S. Blaize and G. Lerondel

Development of a Fourier-transform waveguide spectrometer for space applications, by M. Florjańczyk, C. Alonso-Ramos, P. Bock, A. Bogdanov, P. Cheben, I. Molina-Fernández, S. Janz, B. Lamontagne, A. Ortega-Moñux, A. Scott, K. Sinclair, B. Solheim and D.-X. Xu Silicon photonic MZI sensor array employing on-chip wavelength multiplexing, by P. Muellner, R. Bruck, M. Baus, M. Karl, T. Wahlbrink and R. Hainberger

Towards Si-based electrically injected group-IV lasers, by $G$. Sun

Deep-levels in silicon waveguides: a route to high yield fabrication, by A.P. Knights, J.J. Ackert, D.F. Logan, E. Huante-Ceron and P.E. Jessop

$10 \mathrm{Gbit} / \mathrm{s}$ silicon modulator and germanium detector chip-to-chip optical link, by M. Ziebell, D. Marris-Morini, G. Rasigade, J.-M. Fédéli, E. Cassan and L. Vivien

Integration, processing and performance of low power thermally tunable CMOS-SOI WDM resonators, by I. Shubin, G. Li, X. Zheng, Y. Luo, H. Thacker, J. Yao, N. Park, A.V. Krishnamoorthy and J.E. Cunningham

Semiconductor nanomembranes for integrated silicon photonics and flexible photonics, by W. Zhou, Z. Ma, S. Chuwongin, Y.-C. Shuail, J.-H. Seo, D. Zhao, H. Yang and W. Yang

Picosecond all-optical switching using nonlinear Mach-Zehnder with silicon subwavelength grating and photonic wire arms, by I. Glesk, P.J. Bock, P. Cheben, J.H. Schmid, J. Lapointe and S. Janz.

We thank the contributors for providing these in-depth overviews of their respective topics and new insights into forthcoming developments. We hope that this Special Issue will prove valuable to those working in silicon photonics and nanophotonics and will help in advancing research in this field. 